\title{
A diáspora das congregações femininas portuguesas para o Brasil no início do século XX: política, religião, gênero*
}

Maurício de Aquino**

\section{Resumo}

Neste artigo pretende-se reconstruir historicamente o processo de diáspora de três congregações religiosas femininas portuguesas em decorrência da política religiosa estabelecida pela República de Portugal em 1910. Serão privilegiadas as Irmãs Franciscanas Hospitaleiras, as Irmãs Dominicanas de Santa Catarina de Sena e as Irmãs de Jesus, Maria e José, sobretudo, estas duas últimas que se estabeleceram no estado de São Paulo em 1912. Nesse período, São Paulo já havia despontado como o principal estado do Brasil e, em seus limites, as expansões cafeeira, urbana $e$ ferroviária, envolvidas pela imigração europeia e pela industrialização, abriam novas possibilidades de atuação às mulheres, ainda que a modernização tecnológica não fosse acompanhada no campo das relações de gênero. As mulheres freiras de Portugal se juntaram às outras que aqui estavam $e$ assumiram a gestão de asilos, escolas, faculdades e hospitais, chefiando homens $e$ atraindo mulheres que almejavam outras perspectivas de vida para além daquelas oferecidas pela sociedade civil da época.

Palavras-chave: Diáspora, Mulheres freiras, Gênero e Religião.

\footnotetext{
" Recebido para publicação em 5 de janeiro de 2011, aceito em 17 de abril de 2013. Texto dedicado ao historiador das religiões Eduardo Basto de Albuquerque (in memoriam).

** Professor Adjunto da Universidade Estadual do Norte do Paraná (UENP), campus Jacarezinho. mauriaquino12@uenp.edu.br
} 
The Diaspora of the Portuguese Women's Religious Congregations to Brazil in the Early Twentieth Century: Politics, Religion, Gender

\begin{abstract}
:
This article attempts to reconstruct historically the process of diaspora of three Portuguese Women's Religious congregations as a result of the new religious policy established by the Republic of Portugal in 1910: will be favored Franciscan Hospitaller Sisters of the Dominican Sisters of St. Catherine and the Sisters of Jesus, Mary and Joseph, especially the latter two who have settled in São Paulo in 1910. During this period, St. Paul had already emerged as the leading state in Brazil and its boundaries, the coffee expansion, urbanization, railway, surrounded by European immigration and industrialization, opened new possibilities for working women, although the technological modernization was not accompanied in the field of gender relations. Women sisters from Portugal joined the others who were here and took over the management of nursing homes, schools, colleges and hospitals, leading men and women who longed for attracting other perspectives of life beyond those offered by civil society of the time.
\end{abstract}

Key Words: Diaspora, Nuns Women, Gender and Religion. 
A expulsão das Ordens e Congregações religiosas decorrente do modelo de implantação da República em Portugal, no ano de 1910, resultou na diáspora desses institutos como única estratégia de sobrevivência organizacional, sobretudo, daqueles fundados $e$ restritos ao território luso. Em 1911, as Irmãs Dominicanas de Santa Catarina de Sena e as Irmãs Franciscanas Hospitaleiras dirigiram-se ao Brasil. No ano seguinte, as Irmãs de Jesus, Maria e José fizeram o mesmo. A escolha recaiu sobre um país que mantinha vínculos culturais com Portugal. Duas dessas congregações instalaram-se no mais rico e promissor estado brasileiro da época: São Paulo. Outra se deslocou para o estado do Pará, ainda envolvido por um otimismo progressista por conta dos avanços econômicos proporcionados pelo comércio da borracha.

No ensejo da expansão da rede escolar no Brasil, essas congregações criaram colégios para atender às necessidades de manutenção de seus institutos, à demanda educacional do período $e$ aos projetos romanizadores do catolicismo brasileiro envidado pelo episcopado ultramontano. Ademais, favoreceram o alargamento da vida consagrada feminina que viabilizou novas perspectivas sociais para as mulheres brasileiras. Destarte, pretende-se apontar e discutir, breve e panoramicamente, algumas questões centrais relativas aos contextos sociais e religiosos, aos desafios e às conquistas no processo de estabelecimento dessas congregações no Brasil, contribuindo modestamente para o entendimento dessas diásporas religiosas em tempos de incipiente discussão sobre os papéis sociais de homens e de mulheres no prelúdio da modernidade republicana brasileira.

\section{A implantação da República e a Igreja Católica, no Brasil e em Portugal}

Desde meados do século XIX os Impérios do Brasil e de Portugal estabeleceram leis (a de 1834 em Portugal, e a de 1855 no Brasil) que restringiam a entrada, a ação e a reprodução das ordens e congregações religiosas em seus territórios. Esses atos imperiais podem ser historicamente compreendidos, de um lado, 
pela tradição antijesuítica e anticongregacionista oriunda dos tempos do Marquês de Pombal que fortaleceu práticas regalistas e jansenistas; $e$, de outro, pelo contexto internacional de hostilidade à Santa Sé em decorrência de profundas mudanças religiosas e sociopolíticas marcadas pela ascensão de filosofias e movimentos que contestaram os regimes $e$ as tradições políticas vigentes $e$ as crenças e grupos que as sustentavam no fim do Antigo Regime. Essas filosofias e movimentos atingiram os Impérios do Brasil e de Portugal de modos diferentes, em virtude das especificidades históricas de cada um. Em ambos, a última metade do século XIX caracterizou-se, entretanto, pela entrada e/ou permanência "clandestina" de ordens e congregações religiosas. A proclamação da República deu, contudo, novos rumos a esse processo: no Brasil, a República foi acompanhada da liberalização e da consequente expansão das congregações; em Portugal, o republicanismo vitorioso instalou a repressão $e$ a perseguição às congregações que resultaram em perdas materiais $e$ imateriais, bem como na diáspora.

Comecemos pelo Brasil, que se tornou uma república vinte anos antes desse regime ser implantado em Portugal.

Uma das primeiras tarefas da República brasileira foi a da laicização do Estado, com a publicação do Decreto 119-A, de 07 de janeiro de 1890, que acabou com o regime de Padroado no país. Uma semana após essa publicação, outro decreto foi publicado implantando o calendário republicano que destituía as datas comemorativas religiosas, inclusive a do Natal. O liberalismo, o positivismo e o jacobinismo francês disputavam entre si a direção ideológica do novo regime instalado no Brasil, que precisou de quase uma década para se estabelecer enfrentando rivalidades políticas, institucionais, guerras civis e rebeliões em diferentes partes de um território nacional ainda indefinido em muitos quilômetros de fronteiras. $\mathrm{O}$ episcopado brasileiro, representado por D. Antônio de Macedo Costa (18301891) cuja autoridade foi construída durante o conflito que sustentou contra o segundo imperador brasileiro, D. Pedro II (1825-1891), por não aceitar maçons em irmandades religiosas e 
do qual a Igreja saiu vitoriosa (A "Questão Religiosa" - 1872-1875), criticou, de imediato, a decisão, mas, tão logo percebida a inevitabilidade da situação, passou a negociar junto ao responsável pelos trabalhos da Assembleia Constituinte, o católico e maçom Rui Barbosa (1849-1923), as condições de existência da Igreja no novo regime (Vieira, 2007:335-339).

Aproveitando-se do fato de ter sido professor de Rui Barbosa no Colégio da Bahia, D. Antônio de Macedo Costa escreveu-lhe ainda em dezembro de 1889, no calor da proclamação da República, realizada em 15 de novembro daquele ano, para lembrar-lhe de suas raízes católicas, das promessas de importantes republicanos, como Quintino Bocaiúva (1836-1912) e Marechal Deodoro da Fonseca (1827-1892), acerca da manutenção dos direitos católicos, bem como aconselhar-lhe no sentido de que o novo regime brasileiro se espelhasse no modelo estadunidense, de liberdade religiosa, e não no modelo francês, de perseguição religiosa. As propostas de D. Macedo Costa foram parcialmente aceitas. No mencionado Decreto 119-A ficou estabelecida a total separação entre Estado e Igreja, enfatizando-se o caráter laico da República nascente. Por outro lado, foram garantidos os direitos de liberdade de culto e de manutenção das propriedades eclesiásticas, causas do principal temor do episcopado brasileiro diante dos precedentes históricos de confiscação dos bens da Igreja que acompanhavam a implantação dos regimes republicanos, além de o Estado se responsabilizar, por mais um ano, pelo pagamento das côngruas e outros gastos eclesiásticos; foi uma espécie de ação transitória envidada pelo Estado na mudança de sua relação oficial com a Igreja. Esses direitos foram mantidos na primeira Constituição republicana brasileira, de 1891, indicando, nesse aspecto, a incorporação de reivindicações católicas.

A nova situação ensejou uma efervescência religiosa $e$ administrativa sem precedentes para a Igreja Católica Apostólica Romana no Brasil. A separação "Estado/Igreja" apresentou grandes desafios à instituição eclesial, que deveria lidar agora com o legado de quatrocentos anos de atrelamento ao Estado, 
desamparada em uma conjuntura anticatólica. Mas, propiciou, igualmente, uma liberdade antes inimaginável que sustentava $e$ ensejava novos e autônomos projetos da Igreja no país. Ainda nesse contexto, a Santa Sé assumiu o controle administrativo da Igreja Católica no Brasil, que se consolidou com o Concílio Plenário da América Latina em 1899 (Wernet, 1991:197-200).

É significativo relacionar o mencionado Concílio Plenário com a publicação da carta apostólica Testem benevolentiae, também de 1899, que condenou o "americanismo eclesiológico", isto é, o movimento que desejava modificar os aspectos medievais da Igreja à luz das ideias de progresso e democracia que tomavam forma nos Estados Unidos da América. Para reconstruir o seu lugar na ordem social brasileira, a Igreja priorizou uma reforma interna e a aproximação com os detentores da nova ordem. Nesse sentido, se torna mais aguda a europeização do catolicismo brasileiro, conforme a interpretação do historiador José Oscar Beozzo (2003:279) acerca desse período:

Do mesmo modo que as elites dirigentes do país se subordinam às ideologias dominantes na Europa e nos Estados Unidos, ao liberalismo, ao positivismo, a Igreja vai seguir um caminho paralelo, na sua reforma. Se as elites tornam-se "estrangeiras" na sua cultura, também a Igreja, fazendo vir da Europa uma centena e meia de congregações $e$ ordens religiosas masculinas e femininas, num curto período de trinta anos, vai se europeizar $e$ romanizar, tornando-se estranha à religião luso-brasileira, até então praticada pelo povo e veiculada pela Igreja.

Urge considerar que o catolicismo ultramontano ou romanizado foi uma resposta aos ataques desferidos a Igreja pelos liberais, socialistas e comunistas a partir, sobretudo, da Revolução Francesa. Baseada nos princípios do Concílio de Trento (15451563) ratificados e exacerbados no Concílio Vaticano I (18691870), essa forma histórica do catolicismo se delineou pelo reconhecimento do Papa como autoridade espiritual total, pela 
visão teocrática, pela ênfase no aspecto sobrenatural e devocional, pela clericalização e sacramentalização das práticas religiosas.

A sacralização da figura do Papa e da organização eclesiástica contribuiu e foi alimentada pela expansão do domínio administrativo e simbólico do papado, a partir de uma maior intervenção da Santa Sé no episcopado de diferentes países, em um contexto de perdas territoriais e políticas da Igreja na Europa de fins do século XIX. Esse movimento de centralização da Igreja Católica na Santa Sé, verdadeira reorganização ante a modernidade identificada com o ateísmo na visão eclesial, foi denominado, já no século XIX, como mostra Wernet (1987), pelo termo "romanização" - cunhado pelo teólogo "alemão" Joseph Ignatz von Döllinger (1799-1890), adversário e crítico ferrenho do ultramontanismo.

$\mathrm{Na}$ historiografia brasileira, "romanização" estabeleceu-se como conceito a partir dos trabalhos dos brasilianistas protestantes Roger Bastide e Ralph Della Cava, sendo difundido e consagrado, principalmente, pelos cientistas sociais brasileiros Pedro de Assis Ribeiro de Oliveira, Pe. José Oscar Beozzo, Carlos Rodrigues Brandão, entre outros, não obstante, as críticas, como as do historiador eclesiástico Fr. Dilermando Ramos Vieira, ao seu caráter um tanto agressivo e inadequado (Aquino, 2013). Para Wernet (1987), a romanização se caracterizou, sobretudo, pela integração sistemática da Igreja brasileira, nos planos institucional e ideológico, nas estruturas altamente centralizadas da Igreja Católica, dirigida de Roma. No plano diocesano, ela significou uma centralização do poder religioso na figura do bispo e um reforço da autoridade episcopal sobre o clero regular, secular e associações leigas (Wernet, 1987:176-184). No Brasil, a ação romanizadora iniciou-se já no segundo quartel do século XIX com as práticas de D. Romualdo Seixas, D. Antônio Ferreira Viçoso e D. Antônio Joaquim de Melo, batizados de "bispos reformadores". Porém, foi só na virada dos séculos, após a separação entre Estado e Igreja, que ela se tornou hegemônica institucionalmente (Aquino, 2012).

A reforma ultramontana do catolicismo exigia a ereção de dioceses e paróquias demandando, assim, a criação de uma rede 
de templos, colégios, conventos, santuários, oratórios, palácios episcopais, enfim, que efetivassem a produção e o domínio de um espaço ou território religioso. Para isso, era condição sine qua non "uma ocupação estreita e estruturada da topografia"1, antiga estratégia da Igreja, conforme ensina Jacques Le Goff (2007).

Antes de 1890, a criação dessas circunscrições eclesiásticas dependia do Estado que não as erigia, sobretudo, por razões de ordem econômica. Mas, depois de 1890, a Sé Romana assumiu a responsabilidade pela fundação de novas dioceses $e$ "os bispos brasileiros julgaram ter chegado o momento para expandir esses organismos de poder eclesiástico" (Azzi, 2008:18). Foi o tempo da "diocesanização" do catolicismo no Brasil (Aquino, 2012). Entre 1890 e 1910, as capitais dos estados brasileiros foram transformadas em sedes diocesanas e arquidiocesanas, além das cidades interioranas mais importantes. $\mathrm{O}$ gráfico abaixo indica a expressividade na criação de dioceses nesse período da história brasileira.

Gráfico 1: A expansão do número de arquidioceses e dioceses no Brasil durante a Primeira República (1889-1930).

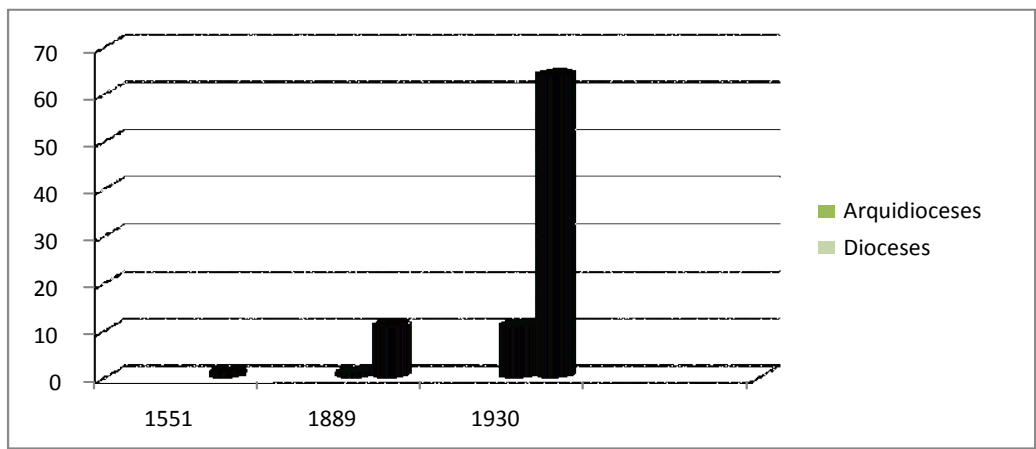

Fonte: Dados do Relatório CERIS - Centro de Estatística Religiosa e Investigação Social, 1965.

${ }^{1}$ Para Le Goff, a concepção cristã de Deus na Idade Média obteve sucesso em virtude da criação e da expansão de uma rede de lugares considerados sagrados (Le Goff, 2007:24). 
A imigração europeia, por motivações sociopolíticas, contribuiu também para a entrada de muitos padres, freiras, freis, frades de várias congregações religiosas femininas e masculinas para atuar junto aos imigrantes, às paróquias, aos hospitais $e$ escolas. Os seminários multiplicaram-se, seminaristas e padres foram enviados para estudo no Colégio Pio Latino-Americano de Roma, e, em 1905, o Brasil foi agraciado com um cardeal, D. Joaquim Arcoverde de Albuquerque Cavalcanti (1850-1930), o primeiro cardeal do Brasil e da América Latina, símbolo da projetada aproximação entre a Cúria Romana e a América do Sul.

Enquanto, no Brasil, os anos 1910 apontavam para uma nova modalidade de relacionamento entre a Igreja Católica e as oligarquias que controlavam o Estado em uma sociedade em constante transformação, sobretudo, pelo trinômio café, ferrovia, imigração, Portugal, por sua vez, experimentava as turbulências da implantação do regime republicano.

Os antecedentes da proclamação da República portuguesa em 05 de outubro de 1910 podem ser encontrados nas crises econômicas e sociopolíticas por que passou a Monarquia lusitana no início dos anos 1890. A crise econômica deveu-se, entre outras razões, pela crise financeira decorrente do "encilhamento" (1891) que impediu a chegada de consideráveis remessas de dinheiro dos portugueses que trabalhavam no Brasil, enquanto que a crise sociopolítica pode ser exemplificada pelo episódio de 11 de janeiro de 1890, quando a Inglaterra lançou o Ultimatum ao governo português quanto à concessão dos territórios coloniais entre Angola e Moçambique (Mapa Cor-de-rosa) ameaçando iniciar uma guerra contra Portugal caso não fosse atendida. Pouco mais de um ano depois desse Ultimatum, em 31 de janeiro de 1891, houve uma tentativa de implantação da república em Portugal, malograda pela falta de apoio popular e parca articulação político-militar.

Mas, em 1910, essas lacunas haviam sido preenchidas após duas décadas de reinados instáveis, ora autoritários, ora constitucionais, com o recrudescimento das disputas ideológicas entre liberais, ultramontanos, maçons e socialistas; período de 
instabilidade também para as ordens e congregações, ora esquecidas, ora apoiadas, ora atacadas pelos grupos e ideologias concorrentes. Nesse contexto, a ideia de República passou a condensar o novo, o moderno, o progresso, enquanto a monarquia passou a indicar o antigo, o ultrapassado, o arcaico.

Em um contexto internacional de ataque ao catolicismo romano, agravado em Portugal pela tradição anticongregacionista, irrompeu uma verdadeira questão religiosa na medida em que, desde 1834, as ordens masculinas estavam extintas e os seus bens confiscados à Fazenda Nacional e as congregações femininas estavam reguladas pelos interesses do Estado.

Vale lembrar, entretanto, que a partir dos anos 1860, essas ordens e congregações começaram a se rearticular discretamente até obterem o fortalecimento $e$ a reabertura de conventos $e$ províncias, atuando junto à família real, bem como em institutos assistenciais e escolares. Assim, no advento da República em Portugal, a Igreja Católica foi associada e identificada à arcaica e perniciosa Monarquia na visão republicana.

Se no Brasil a questão religiosa entre os anos de 1872 e 1875 resultou em dividendos simbólicos para a Igreja, sobretudo, porque passou a ser concebida como dissidente da Monarquia e, acrescente-se a essa razão o fato de as ordens e congregações estarem em decadência no advento da República brasileira, não oferecendo empecilhos e perigos ao novo regime, em Portugal, a situação era diametralmente outra, as congregações estavam fortalecidas e eram concebidas como instrumentos de sustentação da Monarquia no início do século XX.

Tendo surgido e triunfado sobre dois mitos, o da pátria decadente do período monárquico e o do ressurgimento $e$ revitalização modernizantes, a Primeira República portuguesa, segundo o historiador António H. de Oliveira Marques (2001), envidou uma política agressiva que

(...) dirigiu-se, no plano interno, em primeiro lugar contra a Igreja, reconhecida como o baluarte mais perigoso do conservantismo e do reacionarismo. Dirigiu-se igualmente 
contra os monárquicos, contra a oligarquia financeira $e$ econômica, contra o anarco-sindicalismo e a organização operária em geral, contra o caciquismo rural tradicional etc. (Marques, 2001:370).

$\mathrm{Na}$ perspectiva dos republicanos mais exaltados, o apoio eclesiástico ao conservantismo dava-se, sobretudo, pela ação das congregações religiosas. De fato, às vésperas da proclamação da República existiam em Portugal 31 congregações ou associações religiosas distribuídas por 64 casas concentradas no centro e no norte do país. Essas congregações atendiam a vários asilos, dispensários, escolas, orfanatos e hospitais, mantendo o caráter sagrado das ações assistenciais e educacionais.

Ademais, essas congregações atuavam na formação das mulheres, algo que incomodava os republicanos, mas que se tornara a principal característica do catolicismo moderno: a sua "feminização" (Nunes, 1996). De fato, desde a última metade do século XIX, as novas propostas de ação da Igreja voltadas para o atendimento em áreas ainda marcadas pela sacralidade, como a saúde, ou tradicionalmente eclesiais, como a educação, e as mudanças sociopolíticas que aprofundavam e explicitavam as desigualdades sociais ambientaram a criação de várias associações $e$ institutos femininos de vida ativa, isto é, de atuação social. Para os propósitos deste trabalho, destacamos as congregações das Irmãs Dominicanas de Santa Catarina de Sena, Irmãs Franciscanas Hospitaleiras e Irmãs de Jesus, Maria e José criadas nesse contexto e que, nos anos 1910, foram forçadas a emigrar para o Brasil em decorrência da execução da lei republicana portuguesa, de 20 de abril de 1911, de extinção das ordens e congregações.

\section{Congregações portuguesas, educação e sociedade em São Paulo, entre 1911 e 1921}

Fundada em Lisboa, Portugal, em 1868, por Teresa Rosa Fernanda de Saldanha Oliveira e Sousa (1837-1916), mais conhecida por Teresa de Saldanha, as Irmãs Dominicanas de Santa Catarina de Sena (IDSCS) surgiram a partir da Associação 
Protectora das Meninas Pobres, criada em 1859. A Associação e, depois, a Congregação, ocupava-se do ensino e de visitas aos doentes e pobres. Envidou esforços também na alfabetização e na catequização de operários, com aulas noturnas para esses trabalhadores. As ações das IDSCS articulavam variados desejos e projetos: atendimento aos pobres e operários no contexto do capitalismo industrial e da urbanização, o novo ambiente social $e$ religioso, espiritualidade das ordens terceiras de São Domingos de Gusmão e a revitalização dos conventos das Dominicanas contemplativas em risco de extinção.

Em 1910, e, sobretudo, a partir de abril de 1911, as ações das IDSCS foram limitadas pelo governo republicano a duas casas: a da Regeneração de Braga e a do Asilo de Cegas, em Lisboa. Contando com uma religiosa de origem brasileira, Ir. Maria de Santo Inocêncio Lima (1873-1948), que ingressara na congregação em 1908, a Superiora, Madre Teresa Saldanha, deliberou positivamente a respeito da emigração para o Brasil ainda no final de 1911.

No mesmo ano também desembarcaram no Brasil as Irmãs Franciscanas Hospitaleiras da Imaculada Conceição (IFHIC). Essa congregação foi criada em 03 de maio de 1871 com o nome de Congregação das Irmãs Franciscanas Hospitaleiras dos Pobres pelo Amor de Deus. Os fundadores são Madre Maria Clara do Menino Jesus (1843-1899) e Pe. Raimundo dos Anjos Beirão (1810-1878).

No ano seguinte, 1912, chegaram ao Brasil as religiosas da Pia União Jesus, Maria e José ou Irmãs de Jesus, Maria e José (IJMJ). A congregação foi criada pela Madre Rita Amada de Jesus (1848-1913), em 24 de setembro de 1880. Em 2006, Madre Rita Amada de Jesus foi beatificada, com ênfase em sua persistência na obra de evangelização e educação católica, não obstante as perseguições que sofrera no período de ataques à religião em Portugal, entre 1834 e 1934. Com a implantação da República e os atos anticongregacionistas que se avolumaram, Madre Rita se refugiou em sua terra natal, Casalmendinho, de onde reagrupou suas freiras e, com a ajuda do sobrinho e de conhecidos, enviou 
os primeiros grupos de religiosas para o Brasil entre o outubro de 1912 e janeiro de 1913. Nesse ínterim, já no Brasil, foi inaugurado o último colégio sob as ordens da beata, em 8 de dezembro. Madre Rita morreu em 6 de janeiro de 1913, tendo cumprido a tarefa de manter viva a obra que começara. Sua festa é celebrada em 24 de setembro, dia da fundação de seu instituto religioso.

Essas congregações escolheram um país de fortes tradições culturais portuguesas, sobretudo, na língua e na religião, e no qual existiam comunidades lusitanas consolidadas. Ademais, a antiga colônia portuguesa passava por um momento de estabilidade econômica baseada na exportação do café, na expansão da malha ferroviária, na industrialização e na modernização com expressivo investimento de capital estrangeiro. As crises $e$ revoluções asiáticas e europeias, aliadas ao aumento demográfico da última metade do século XIX, proporcionaram um fenômeno de migração internacional sem precedentes nesse período que denominado Era das Grandes Migrações. Pelas razões expostas, nessa era muitos migrantes portugueses escolheram o Brasil, conforme aponta o pesquisador Joaquim da Costa Leite:

$\mathrm{Na}$ era das grandes migrações da segunda metade do século XIX e começos do século XX, a emigração portuguesa foi transatlântica, tendo o Brasil como destino principal, quase exclusivo. De 1855 a 1914, as estatísticas portuguesas registraram um pouco mais de 1,3 milhões de saídas. O Brasil atraiu oitenta a noventa por cento desses emigrantes; apenas uns 200 mil escolheram outros destinos, rumando à América do Norte, Argentina, Guiana Britânica, e Hawaí (Leite, 2000:177).

A Igreja do Brasil, como discutido anteriormente, também passava por transformações, pois se movimentava em sua construção institucional desencadeada pela separação legal entre o Estado e a Igreja no início do regime republicano, precisamente no dia 7 de janeiro de 1890. Esse movimento manifestava-se, principalmente, na expansão do número de dioceses e paróquias para atender e marcar a presença católica na sociedade. De fato, a 
instalação dessas circunscrições foi um marco naquela reorganização eclesiástica brasileira.

Os posicionamentos do episcopado foram ambíguos quanto à separação, situando-se entre o lamento da perda de privilégios e a ovação pela liberdade institucional. Num encontro de interesses $e$ necessidades, a Igreja do Brasil se alinhou definitivamente às estruturas administrativas da Sé Romana. Para o Vaticano era fundamental contar com a fidelidade da significativa Igreja do Brasil às diretrizes romanas; para a hierarquia eclesiástica brasileira eram imprescindíveis o apoio, o modelo e o capital simbólico da Sé Romana, considerada sede espiritual e institucional do catolicismo. Para afirmar-se e intervir em uma sociedade que se transformava em ritmo próprio, mas a reboque dos padrões civilizadores europeus, era premente atuar na área tradicional da Igreja, a educação, bem como em setores ainda envolvidos pela sacralidade, como a saúde, e em outros abandonados pelo Estado, como as obras de assistência social. Como na Europa do século XIX, aqui também essas práticas sociais e religiosas auferiram capitais simbólicos e patrimoniais para a Igreja. Nesse movimento destacam-se as congregações religiosas femininas.

Entre 1890 e 1930, foram criadas ou chegaram ao Brasil 93 congregações religiosas femininas, destacando-se numericamente as de origem francesa, com 28 institutos, as de origem italiana, com 24 institutos, $e$ as fundadas no Brasil, 22 institutos, segundo as informações do Relatório CERIS de 1965. Mas o número deve ter sido maior do que apresentado nesse relatório, conforme apontam pesquisas monográficas mais recentes. Esses institutos ensejaram às mulheres freiras a oportunidade sui generis de assumir cargos de chefia em setores axiais da vida pública como escolas, hospitais, faculdades e obras de assistência social (Nunes, 2008).

Ainda que a moral europeia patriarcal predominasse, as congregações religiosas femininas ofereceram educação e espaço para as mulheres atuarem na vida pública, e intervieram, em moldes cristãos, no debate da época concernente aos direitos da mulher (Pinto, 2003). O direito de voto feminino estabelecido no 
Brasil em 1932 resultou também dessa ativa presença dos institutos de vida consagrada feminina e do novo papel da mulher nos projetos da Igreja.

$\mathrm{O}$ rápido crescimento do número de religiosas brasileiras nos institutos de origem europeia e a criação de tantas congregações femininas no país na primeira metade do século XX podem ser explicados por esse chamariz: a possibilidade de realização espiritual e humana da mulher em uma sociedade ainda patriarcal.

Gráfico 2: A entrada de congregações religiosas estrangeiras no Brasil entre 1890 e 1922.

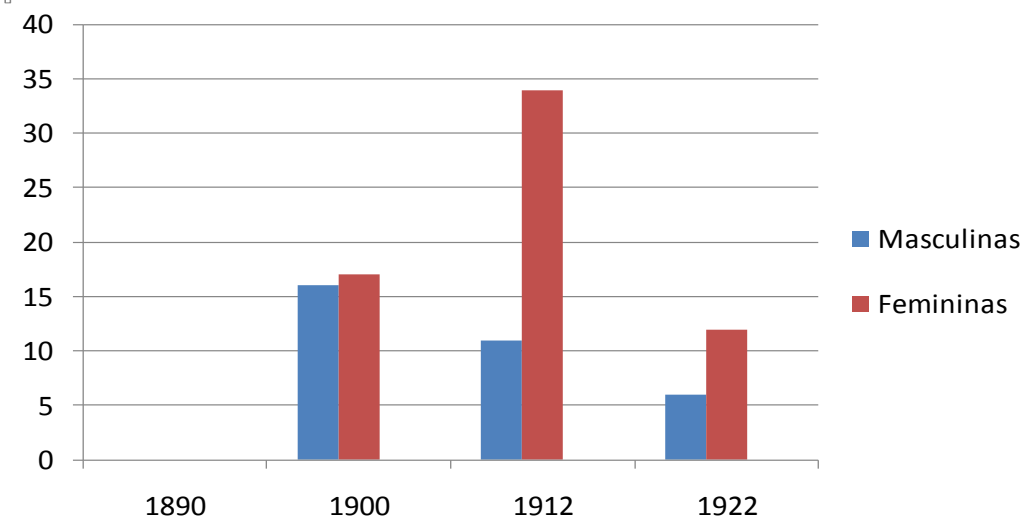

Fonte: Relatório CERIS, 1965.

Os anos 1910 foram tempos de maior entrada de congregações religiosas femininas no Brasil: nove no total. Os dados do relatório CERIS informam serem três delas portuguesas, mas hoje sabemos que devem ter sido pelo menos seis. As IDSCS $e$ as IJMJ optaram por um estado brasileiro em ascensão: São Paulo. Em análise clássica, o historiador estadunidense Joseph Love (2006) considerou a partir de suas pesquisas sobre a singularidade do crescimento econômico paulista: 
De início, naturalmente, foram as exportações de café que deram a São Paulo a sua prosperidade. Em 1907, a metade do café do mundo era cultivada em São Paulo (e três quartas partes em todo o Brasil). Por volta de 1920, o Estado também era o primeiro do país em produção industrial. O fato de São Paulo passar a exportar para outros Estados brasileiros em 1931 - assim continuando dali por diante - foi uma indicação importante, conquanto indireta, do seu desenvolvimento industrial. Em 1939, a indústria suplantara a agricultura em São Paulo como fator de produção (Love, 2006:59).

Essa prosperidade paulista ensejava a demanda escolar que as religiosas desejavam e precisavam para a criação de seus colégios. Vale lembrar, ainda, que o êxito educacional das francesas Irmãs de São José de Chambery à frente do Colégio do Patrocínio, fundado em Itu, no interior do estado, no ano de 1858, fez com que as oligarquias se sentissem atraídas pela educação feminina dispensada por freiras estrangeiras. Esse Colégio do Patrocínio situava-se na diocese de Campinas, a mesma onde se instalaram as IDSCS e as IJMJ. Em um país que havia abolido a escravidão há pouco mais de vinte anos, por outro lado, urgia a presença de professoras disciplinadas e cultas. Ademais, a própria criação desses colégios dirigidos pelas freiras europeias era considerada como um sinal de progresso e modernização.

As IFHIC se estabeleceram na diocese de Santarém, no estado do Pará, em tempos de grande desenvolvimento local ativado pela economia da borracha e pelos investimentos na região Norte do Brasil, durante a construção da ferrovia MadeiraMamoré. Mas era ainda uma área extremamente atrasada em termos de cultura material na comparação com a Europa (Lima, 1999). As IFHIC sentiram os efeitos dos contrastes climáticos e de sociabilidade, muitas adoeceram, outras faleceram. Porém, a Congregação perseverou em seus objetivos construindo colégios e atendendo às necessidades religiosas locais.

Por outro lado, urge apontar, essa rede escolar católica trazia compensações econômicas e viabilizava, como nenhuma 
outra estratégia, o projeto de recatolização da sociedade brasileira, e sustentava as congregações emigrantes. Não eram escolas voltadas apenas para os ricos, afinal, havia bolsistas pobres como Juscelino Kubitschek que fora um deles em Minas Gerais. Mas, como mecanismo de sustentação econômica da diocese e da congregação religiosa, era fundamental o pagamento das mensalidades escolares, o que só os ricos, e os pobres com o auxílio proveniente do Estado ou de benfeitores, poderiam fazer. A educação, com efeito, mediou por vezes nesse período, o embate da Igreja com os grupos sociais que assumiam a modernidade, numa atuação que indica a ambígua recepção da modernidade no Brasil. Aceitavam-se alguns princípios políticos e recursos tecnológicos da modernidade conservando, no entanto, os costumes e valores patriarcais.

A elite que combatia a intervenção da Igreja na ordem política financiava a mencionada rede escolar católica, matriculando seus filhos e filhas em colégios de "europeus" padres, freiras e professores italianos, franceses, belgas, portugueses etc., no espírito da Belle Époque, e desprezava a criação de escolas públicas. O historiador Ivan Aparecido Manoel considera que:

(...) se a Igreja ia buscar apoio financeiro e político junto à oligarquia, a oligarquia lhe amparou decididamente porque sabia que o seu projeto educacional, e mesmo o conjunto da política ultramontana, lhe era duplamente favorável: primeiro, porque lhe reservava a função de dirigente da sociedade, cabendo-lhe, assim, a produção das idéias norteadoras do conjunto social. Segundo, porque o discurso antimoderno do catolicismo ultramontano tanto lhe garantia a execução de um projeto educacional não comprometedor e uma doutrinação de passividade, quanto, de fato, não obstava os necessários avanços e modernizações no âmbito das forças produtivas (Manoel, 1996:102).

Eis os quadros sociopolíticos e religiosos dos anos 1910, quando da vinda das congregações portuguesas para o Brasil. 
Essas congregações favoreceram a abertura da vida religiosa feminina, sendo muito mais abertas à entrada de brasileiras, aliás, do que as ordens masculinas à entrada de brasileiros. O gráfico 3 apresenta os índices do crescimento exponencial do total de freiras no Brasil entre 1872 e 1920 com destaque para a quantidade de freiras nascidas no Brasil superar o número de freiras estrangeiras em 1920.

Gráfico 3: Freiras brasileiras e estrangeiras no Brasil em 1920.

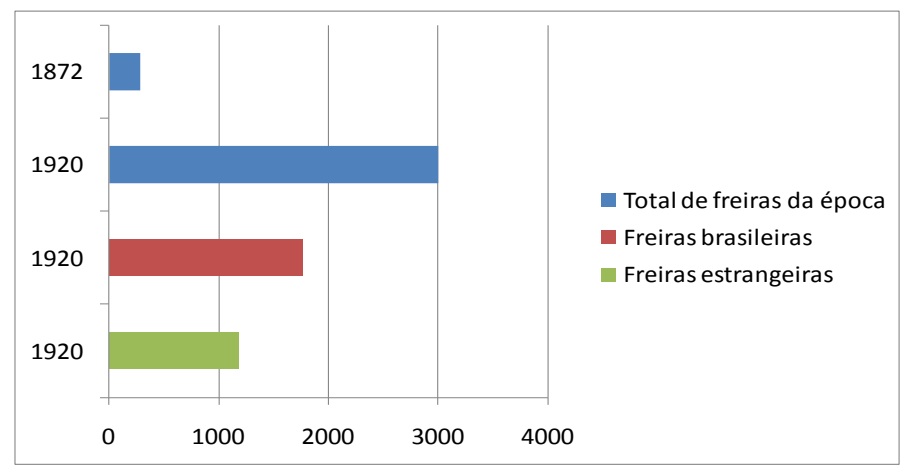

Fonte: Beozzo, 2006:40.

As IDSCS chegaram ao Brasil no final de 1911 e, no início de 1912, já dirigiam um pensionato em Campinas, uma creche em Amparo, o Hospital da Misericórdia em Piracicaba, além de uma escola e de uma casa de crianças no Estado do Rio de Janeiro. Em 1916, a congregação já tinha seis casas consolidadas no Brasil e, em 1921, foi criado o famoso Colégio da cidade de Limeira, onde atuou a irmã brasileira Maria do Santo Inocêncio Lima. O governo municipal deu a uma escola pública o seu nome, em homenagem de reconhecimento ao trabalho educativo dessa religiosa e de outras que liderou como vigária geral do Brasil.

As IFHIC, depois de passarem pela Espanha, se estabeleceram na diocese de Santarém, no Pará, a pedido do bispo local que era um franciscano alemão. Como se viu, elas criaram escolas e atenderam às necessidades religiosas locais. Em 1913, elas 
já haviam se expandido para o nordeste brasileiro fundando colégios em importantes capitais: Aracaju, Maceió e Salvador.

As IJMJ chegaram em 1912, fundando um colégio ainda no mês de dezembro daquele ano. Após instalarem-se na cidade de Igarapava, no interior paulista, as irmãs deram continuidade ao trabalho na assistência social e na educação. $\mathrm{O}$ empenho resultou na construção de um importante colégio na cidade de Franca no ano de 1919.

\section{A diáspora das congregações portuguesas e as mulheres no Brasil do início do século XX: algumas reflexões}

A histórica presença e a atuação das ordens e congregações portuguesas foram concebidas como o principal obstáculo a ser superado pela República no projeto defendido para modernizar Portugal a partir de 1910. No Brasil, entretanto, a implantação da República rompeu com os vínculos do padroado, impediu o ensino religioso nas escolas públicas, defendeu publicamente o caráter laico do Estado, mas não perseguiu as ordens $e$ congregações religiosas, institucionalmente fragilizadas em 1890, muito menos lhe confiscou os bens ou imiscui-se em seus assuntos diretamente. Em alguns casos, estratégicos para o Estado brasileiro, as subvenções às ordens e congregações instaladas em regiões de fronteiras, como na Amazônia, foram mantidas regime republicano adentro (Aquino, 2012).

Os liberais e maçons portugueses, tão logo instalada a República, iniciaram o processo de cerceamento e extinção das ordens e congregações. Na Era das Grandes Migrações, as congregações femininas das IDSCS, das IFHIC $e$ das IJMJ escolheram o Brasil como lugar de extensão, e mesmo de sobrevivência, de seus institutos. País que em 1912 completava apenas 90 anos de emancipação político-administrativa, de laços rompidos com Portugal, o Brasil vivia tempos de estabilidade e crescimento econômico, sobretudo, em São Paulo, a "locomotiva do Brasil", na imagem consagrada pelo historiador Joseph Love. 
Em São Paulo já viviam milhares de portugueses e outros tantos emigrados europeus e asiáticos que se aproveitavam $e$ contribuíam do/para o desenvolvimento paulista. Em ritmo acelerado de crescimento, todo o Estado de São Paulo se transformava a partir das relações sociais oriundas da articulação de três fatores principais: café, ferrovia e imigração. As elites locais queriam educar seus filhos e filhas em colégios de padrões europeus, o que aumentou a demanda pelas escolas criadas pelas congregações estrangeiras.

Vale lembrar que nesse contexto, mais precisamente no ano de 1910, foi criado o Partido Republicano Feminino representando um momento de ruptura na história das mulheres no Brasil visto ser a primeira organização política feminina em tempos de negação de direitos políticos às mulheres (Pinto, 2003: 18). Ainda nos anos 1910 emergiram movimentos de destaque em favor dos direitos da mulher encabeçados por Bertha Lutz e Maria Lacerda de Moura representantes de duas maneiras distintas de ações feministas do período: a primeira, de Bertha Lutz, integrante da elite econômica e intelectual alinhada ao sistema político do 'liberalismo patriarcal' com reivindicações restritas ao direito de voto; a segunda, de Maria Lacerda, anarquista, voltada para a ruptura com o sistema vigente propondo integral emancipação da mulher no conjunto da classe trabalhadora (Pinto, 2003: 23-37).

Foi nesse ambiente sociopolítico das relações de gênero que se desenvolveram os trabalhos das mulheres freiras vinculadas às congregações portuguesas em diáspora no Brasil. Com os seus institutos e com o acolhimento de mulheres brasileiras em suas corporações, as ações dessas irmãs contribuíram para o crescimento da educação no Brasil e também para o início da transformação do papel social da mulher na sociedade brasileira, ainda que pelo viés conservador da moral católica, um 'feminismo católico', em concorrência com os modelos liberal e anarquista do período. 


\section{Referências bibliográficas}

ALBUQUERQUE, Eduardo Basto de. A história das religióes. In: USARSKI, Frank (org.). O espectro disciplinar da ciência da religião. São Paulo, Paulinas, 2007, pp.19-52.

Aquino, Maurício de. Modernidade republicana e diocesanização do catolicismo no Brasil: as relações entre Estado e Igreja na Primeira República (1889-1930). Revista Brasileira de História [online], São Paulo, vol.32, n. 63, 2012, pp.143-170.

AQUINO, Maurício de. O conceito de romanização do catolicismo e a abordagem histórica da Teologia da Libertação. Horizonte: Revista de Estudos de Teologia e Ciências da Religião, PUC, Belo Horizonte, MG, vol.11, 2013, pp.1485-1505.

Azzi, Riolando (org.). A vida religiosa no Brasil: enfoques históricos. São Paulo, Editora Paulinas, 1983.

AzzI, Riolando. Presença da Igreja na sociedade brasileira e formação das dioceses no período republicano, In: SOUZA, Rogério L. e OTTO, Clarícia (orgs.). Faces do catolicismo. Florianópolis-SC, Editora Insular, 2008, pp.17-40.

BEOzzo, José Oscar. A Igreja entre a Revolução de 1930, o Estado Novo e a Redemocratização, In: PIERUCI, Antônio F. et alii. O Brasil Republicano, vol.11. 2.ed. Rio de Janeiro, Bertrand Brasil, 2003, pp.273-341. Coleção História Geral da Civilização Brasileira.

BEOZzO, José Oscar. Padre José Marchetti: trabalhos, sonhos e morte no Brasil - 1894-1896. In: BRANDÃO, Sylvana (org.). História das religiões no Brasil. Recife-PE, Editora da UFPE, 2006, pp.19-84.

LE Goff, Jacques. O Deus da Idade Média. Rio de Janeiro, Civilização Brasileira, 2007. [Tradução de Marcos de Castro]

LEITE, Joaquim da Costa. O Brasil e a emigração portuguesa (1855-1914). In: FAUSTO, Bóris (org.). Fazer a América: A Imigração em Massa para a América Latina. 2.ed. São Paulo, Editora da USP, 2000, pp.177-199.

LIMA, Nísia Trindade. Um sertão chamado Brasil. Rio de Janeiro, Revan, IUPERJ, UCAM, 1999. 
LOVE, Joseph. Autonomia e interdependência: São Paulo e a Federação Brasileira - 1889-1937. In: CARDOSO, Fernando Henrique et alii (orgs.). O Brasil Republicano, vol.8. Rio de Janeiro, Bertrand Brasil, 2006. Coleção História Geral da Civilização Brasileira.

MANOEL, Ivan Aparecido. Igreja e educação feminina (1859-1919). São Paulo, Editora da Unesp, 1996.

MARQUES, António H. de Oliveira. Da Monarquia para a República. In: TEngarRINHA, José (org.). História de Portugal. 2.ed. Bauru-SP, Editora da USC; São Paulo, Editora da Unesp; Portugal, Instituto Camões, 2001, pp.361-374.

NETO, Vítor. Igreja Católica e anticlericalismo (1858-1910). In: HOMEM, Amadeu C.; SILVA, Armando M. da; ISAÍA, Artur C. (coords.). Progresso e Religião: a República no Brasil e em Portugal - 18891910. Uberlândia, Editora da UFU; Coimbra, IU, 2007, pp.165-191.

NUNES, Maria José F. Rosado. Mulheres e catolicismo no Brasil: uma questão de poder. In: QUEIROZ, José J. et alii. Interfaces do Sagrado. São Paulo, Editora Olho d'Água, 1996, pp.74-96.

NUNES, Maria José F. Rosado. Freiras no Brasil. In: DEL PRIORE, Mary (org.). História das mulheres no Brasil. 9.ed. São Paulo, Editora Contexto, 2008, pp.482-509.

NUNES, Maria José F. Rosado. Prática político-religiosa das congregações femininas no Brasil - uma abordagem histórico-social. In: BEOzzO, José Oscar, Azzi, Riolando (orgs.). Os religiosos no Brasil: enfoques históricos. São Paulo, Editora Paulinas, 1986, pp.188-218.

PINTO, Célia Regina Jardim. Uma história do feminismo no Brasil. São Paulo, Editora Perseu Abramo, 2003.

SoUZA, Wlaumir Doniseti de. Anarquismo, Estado e pastoral do imigrante. São Paulo, Editora da Unesp, 2000.

VIEIRA, Dilermando Ramos. O processo de reforma e reorganização da Igreja no Brasil (1844-1926). Aparecida, SP, Editora Santuário, 2007.

WeRnET, Augustin. A Igreja Paulista no século XIX: A Reforma de D. Antônio Joaquim de Melo (1851-1861). São Paulo, Ática, 1987. 
WERNET, Augustin. O auge da romanização: o Concílio Plenário da América Latina. Anais da X Reunião da Sociedade Brasileira de Pesquisa Histórica, Curitiba-PR, 1991, pp.197-2. 